Case Report

\title{
Diagnosis and Management of Lemierre's Syndrome Presented with Multifocal Pneumonia and Cerebral Venous Sinus Thrombosis
}

\author{
Yasar Sattar ${ }^{D},{ }^{1}$ Ammu Thampi Susheela, ${ }^{2}$ Bibek Karki, ${ }^{3}$ Adnan Liaqat, ${ }^{4}$ Waqas Ullah, \\ and Fnu Zafrullah ${ }^{6}$ \\ ${ }^{1}$ Department of Internal Medicine, Icahn School of Medicine at Mount Sinai-Elmhurst Hospital, Queens, NY, USA \\ ${ }^{2}$ Department of Internal Medicine, Beth Israel Deaconess Medical Center, Boston, MA, USA \\ ${ }^{3}$ Department of Pulmonary and Critical Care, Mayo Clinic, Rochester, MN, USA \\ ${ }^{4}$ Department of Internal Medicine, Nexus Specialty Hospital, The Woodlands, TX, USA \\ ${ }^{5}$ Department of Internal Medicine, Abington Hospital Jefferson Health, Abington, PA, USA \\ ${ }^{6}$ Department of Internal Medicine, Steward Carney Hospital, Tufts Medical Center, Boston, MA, USA
}

Correspondence should be addressed to Yasar Sattar; sattary@nychhc.org

Received 3 September 2019; Accepted 16 January 2020; Published 10 March 2020

Academic Editor: Gloria Taliani

Copyright (c) 2020 Yasar Sattar et al. This is an open access article distributed under the Creative Commons Attribution License, which permits unrestricted use, distribution, and reproduction in any medium, provided the original work is properly cited.

\begin{abstract}
A 27 -year-old female patient initially presented with fever, myalgia, sore throat that progressed to multifocal pneumonia, and cerebral sinus venous thrombosis. A combination of upper respiratory symptoms with tooth infection, positive blood culture for Fusobacterium nucleatum, computed tomography (CT) chest finding of multifocal pneumonia, and magnetic resonance imaging (MRI) finding of internal jugular vein thrombosis (IJVT) and cerebral venous sinus thrombosis (CVST) suggested Lemierre syndrome. The patient was managed with fluids, antibiotics, and anticoagulants. The patient survived and discharged from the hospital. The patient's symptoms improved at 2 months of follow-up.
\end{abstract}

\section{Introduction}

Lemierre's syndrome is a rare disease, caused by the anaerobic bacteria Fusobacterium, most commonly F. necrophorum but occasionally F. nucleatum, F. mortiferum, and F. varium and is a rare fatal complication of acute oropharyngeal infection that can have up to $90 \%$ mortality [1]. Courmont and Cade reported the first case of Lemierre's syndrome in 1890 . It affects 1 in a million population with $90 \%$ mortality [2]. It commonly affects adolescents or young adults of mean age $19-22$ years with male $(2: 1)$ predominance $[3,4]$. The case reports of Lemierre's syndrome are on the rise.

The source of primary infection can be in the chest, teeth, sinuses, and ears or trauma or head and neck malignancies. It manifests as metastatic septic emboli, with a tendency to rapidly involve organs such as lungs followed by liver, spleen, kidney, joints, soft tissues, and brain [3, 5]. It commonly presents with septic thrombophlebitis of the internal jugular vein and metastatic foci of infection [6]. The diagnosis of Lemierre's syndrome is based on the clinical presentation, a positive microbial culture, and a positive radiological finding.

\section{Case Presentation}

A 27-year-old female presented to the urgent care with 3 days of fever, generalized myalgia, and sore throat. At the urgent care, she did not receive antibiotics and was symptomatically managed. Her sore throat improved in a day but developed neck pain and hematuria that prompted her to visit emergency department (ED) after 2 days. She denied any other symptoms or any significant past medical history. 
On general examination, she was alert, oriented to time, place, and person. She was febrile $101^{\circ} \mathrm{F}$, stable blood pressure, stable heart rate, and $\mathrm{SaO}_{2}$ of $98 \%$ on room air. The patient had nonexudative erythematous pharynx and lateral neck tenderness. On auscultation, a systolic flow at the left upper sternal border and bilateral diffuse crackles in the lungs were heard. Splenomegaly was absent. Neurological examination was intact.

On admission, the laboratory study showed a white cell count of $21.6 \times 10^{3}$ cells $/ \mathrm{microL}$ with $89.5 \%$ neutrophils, positive left shift, platelet of $9 \times 10^{3} / \mathrm{microL}$, and hemoglobin of $10.0 \mathrm{~g} / \mathrm{dL}$ with normal mean corpuscular volume. The reticulocyte count was normal, lactate dehydrogenase (LDH) was $210 \mathrm{U} / \mathrm{L}$, and haptoglobin was $306 \mathrm{mg} / \mathrm{dL}$. A peripheral smear showed normal red blood cell morphology, toxic granulation, and few giant platelets. Renal function showed increased blood urea nitrogen (BUN) $57 \mathrm{mg} / \mathrm{dl}$, increased creatinine $3.43 \mathrm{mg} / \mathrm{dl}$, and decreased eGFR $16 \mathrm{ml} / \mathrm{min} / 1.73 \mathrm{~m}^{2}$ and sodium $131 \mathrm{mEq} / 1$. Urinalysis showed gross hematuria with no RBC cast and negative nitrite/esterase. Arterial blood gas analysis revealed respiratory alkalosis with $\mathrm{pH}$ 7.482, $\mathrm{pCO}_{2} 30$, normal bicarbonate, and anion gap.

Infectious workup includes blood culture positive for Fusobacterium nucleatum and negative rapid streptococcal test, throat culture, monospot test. Fecal leukocytes and ova/ parasites tests were negative. A fungal workup was negative for histoplasma, blastomycosis, cryptococcus, and tuberculosis.

An initial chest X-ray is shown in Figure 1.

Positive findings on chest CT and MRI venogram are shown in Figures 2 and 3, respectively. CT abdomen/pelvis and transthoracic echocardiography findings were normal.

Venous imaging to see septic thrombophlebitis include upper extremity/neck venous duplex is shown in Figure 4.

Partial thromboplastin time was 26.4 seconds, D-dimer was $1223 \mathrm{ng} / \mathrm{ml} \mathrm{DDU}$, and fibrinogen was $752 \mathrm{mg} / \mathrm{dL}$. The anticardiolipin antibody was positive, with an IgM level of 15.7 and low protein $C$ with a level of 51 (normal 74-150\%). An autoimmune workup for secondary causes of hypercoagulation was ruled out including lupus, factor-V Leiden mutation, and malignancy.

The patient was initially managed with fluids, broadspectrum antibiotics such as meropenem and bridging mechanical ventilation in the intensive care unit. After imaging and blood culture were suggestive of Lemierre's syndrome, the patient was immediately started on piperacillin/tazobactam $4.5 \mathrm{gm}$ IV 6 hourly and heparin drip with a goal aPTT of 60-80 seconds. The patient's symptoms significantly improved with this antibiotic regimen and anticoagulation. Heparin was switched to warfarin with a goal INR of 2-3, and piperacillin/tazobactam switched to clindamycin $300 \mathrm{mg}$ q6hr with probiotic for 3 weeks for extended coverage of infection.

During the 2 months of follow-up, the patient had a complete resolution of symptoms, a positive beta-glycoprotein but normal IgM level. The patient was then scheduled for repeat MRI venogram in three months.

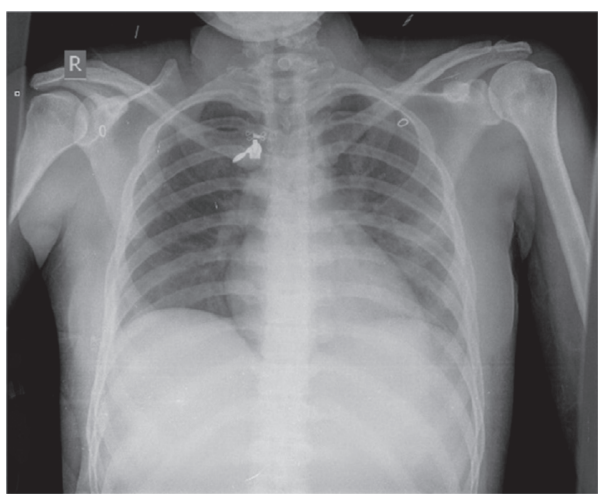

Figure 1: Chest radiography showing left lower and middle lobe pneumonia and a clear right lung.

\section{Discussion}

The three classic criteria, i.e., a history of recent oropharyngeal infection, internal jugular venous thrombosis (IJVT) (clinical or radiological), and positive culture of Fusobacterium nucleatum should now be amended to include only the first two and start treating as presumed LS without waiting for the culture results which may delay diagnosis and treatment with increased risk of mortality.

In this case report, we presented a rare case of Lemierre's syndrome due to Fusobacterium nucleatum that can have potentially lethal consequences. Although there was no headache, which is also a classic presentation of the disease, the treating team was able to diagnose and provide timely treatment to the patient. Tenderness and stiffness on the lateral side of the neck along with a history of sore throat should elicit a high suspicion of Lemierre's disease. Hematuria in this patient is due to the metastatic septic emboli to the kidney. An accurate diagnosis by microbial cultures and imaging (CT/MRI and ultrasound) can facilitate aggressive treatments and favorable outcomes.

Once the oropharyngeal infection is established, $F$. nucleatum can penetrate through the facial planes or the lymphatic system to the nearby vasculature, potentially causing thrombosis as well as thrombophlebitis [7]. The internal jugular vein is usually involved due to the proximity to the peritonsillar space. In our case of Lemierre's disease caused by F. nucleatum, the right internal jugular vein, right transverse sinus, and sigmoid sinuses were involved. Our study involving F. nucleatum is the second case that showed the spread of the infection from the oropharynx into the right transverse sinus despite a relatively early diagnosis. As infection with $F$. nucleatum progresses extremely quickly, these patients should be treated with extreme caution. There are a few other aerobes, such as E. coli, Streptococcus, and Staphylococcus capable of causing Lemierre-like syndrome (LLS), which can also have very dangerous consequences [8].

Treatment of Lemierre's syndrome involves fluid resuscitation and prolonged antibiotic therapy. There have been reports that recannulation of the internal jugular vein or early use of anticoagulation can help with the penetration of antibiotics and increase the efficacy of the treatment [7,9]. The choice of anticoagulant in Lemierre's syndrome has not 


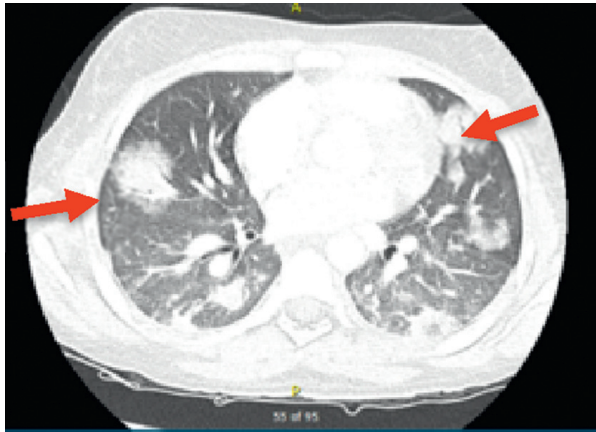

(a)

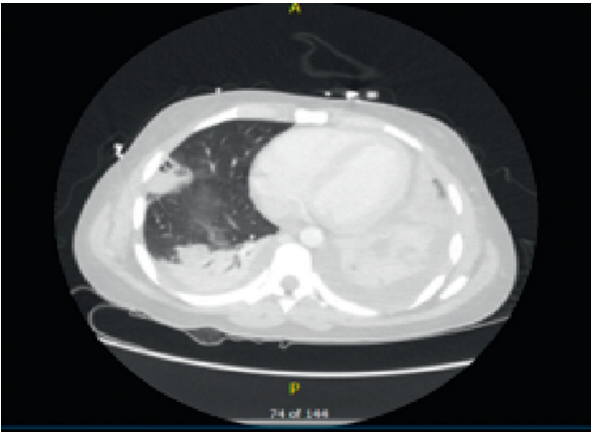

(b)

Figure 2: (a) High resolution CT chest showing septic nodules (red arrows) and bilateral pulmonary infiltrates. (b) CT chest showing bilateral pleural effusion with cavitary lesion likely septic thrombi largest of $4.4 \mathrm{~cm}$.

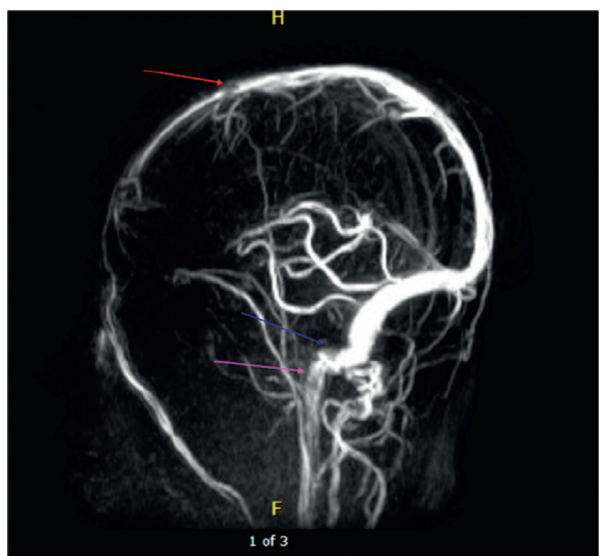

FIGURE 3: MRI venogram showing thrombus in the right sigmoid sinus (blue arrow), thrombus in the superior sagittal sinus (red arrow), and thrombus in the right jugular bulb (pink arrow).

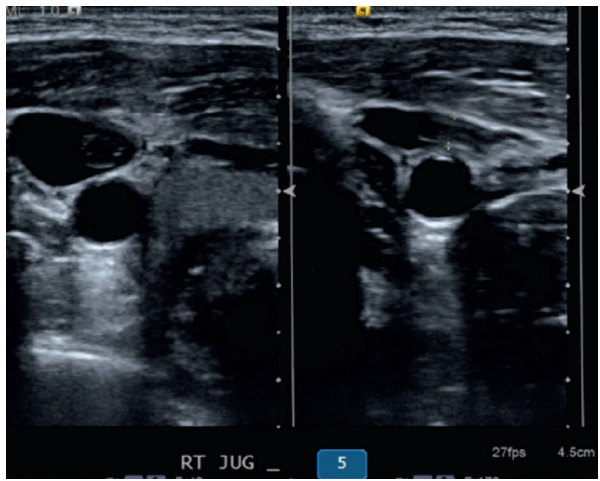

(a)

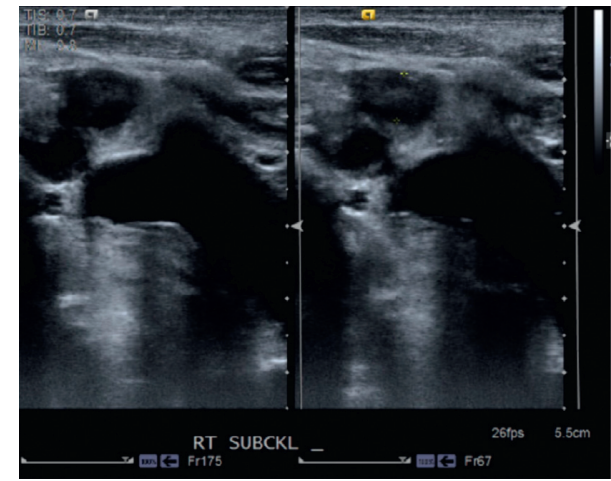

(b)

Figure 4: Venous duplex of the neck showing partially obstructed thrombus in the right internal jugular vein and right subclavian vein.

been established due to its rarity. Prolonged use of anticoagulation can worsen prognosis as it can release septic emboli.

There have been only less than 160 case reports that have been published after its first reporting as a case series in 1936. There have been a handful of case reports published that have implicated Fusobacterium nucleatum as a cause of Lemierre's syndrome. After careful review of the several case reports, the differences in disease processes by F. nucleatum bacteria have been compiled in the following Table 1 .

Although Lemierre initially denoted the case fatality to $90 \%$, a case series by Riordan et al. reports the fatality 
TABLE 1: Literature review of the reported cases on Lemierre syndrome with clinical presentation and management.

\begin{tabular}{|c|c|c|c|c|c|c|c|c|c|}
\hline & Authors & Age/sex & Presentation & $\begin{array}{l}\text { Thrombosis } \\
\text { site }\end{array}$ & Diagnosis & Management & Outcomes & Follow-up & Ref \\
\hline Case 1 & $\begin{array}{l}\text { Williams, } \\
\text { et al. }\end{array}$ & $19 \mathrm{y} / \mathrm{M}$ & $\begin{array}{l}\text { Fever, rigors, sore } \\
\text { throat, pleuritic } \\
\text { chest pain, and } \\
\text { productive cough } \\
\text { with blood- } \\
\text { tinged sputum, } \\
\text { nausea, vomiting }\end{array}$ & $\begin{array}{c}\text { Right } \\
\text { external } \\
\text { jugular vein } \\
(\mathrm{EJV})\end{array}$ & $\begin{array}{l}\text { Blood culture } \\
\text { showed } \\
\text { Fusobacterium } \\
\text { nucleatum }\end{array}$ & $\begin{array}{l}\text { Ampicillin- } \\
\text { sulbactam, } \\
\text { heparin }\end{array}$ & $\begin{array}{l}\text { Complete } \\
\text { resolution of } \\
\text { symptoms } \\
\text { on day } 5\end{array}$ & $\begin{array}{l}\text { Patient did } \\
\text { not follow-up }\end{array}$ & {$[10]$} \\
\hline Case 2 & $\begin{array}{l}\text { Takahashi, } \\
\text { et al. }\end{array}$ & $73 \mathrm{y} / \mathrm{M}$ & $\begin{array}{l}\text { Fever, occipital } \\
\text { pain, diplopia, } \\
\text { and right ptosis }\end{array}$ & $\begin{array}{l}\text { Left internal } \\
\text { jugular vein }\end{array}$ & $\begin{array}{l}\text { Blood culture } \\
\text { showed } \\
\text { Fusobacterium } \\
\text { nucleatum }\end{array}$ & Antibiotics & $\begin{array}{l}\text { Complete } \\
\text { resolution of } \\
\text { symptoms }\end{array}$ & $\begin{array}{c}\text { Not } \\
\text { mentioned }\end{array}$ & {$[11]$} \\
\hline Case 3 & $\begin{array}{l}\text { Wong, } \\
\text { et al. }\end{array}$ & $21 \mathrm{y} / \mathrm{F}$ & $\begin{array}{c}\text { Sore throat, } \\
\text { nausea, vomiting, } \\
\text { and fever, swollen } \\
\text { neck glands, right } \\
\text { ear pain, } \\
\text { dysphagia, dry } \\
\text { cough, } \\
\text { palpitations, back } \\
\text { pain, and orange } \\
\text { urine } \\
\text { discoloration }\end{array}$ & $\begin{array}{c}\text { Internal } \\
\text { jugular vein }\end{array}$ & $\begin{array}{l}\text { Blood culture } \\
\text { showed } \\
\text { Fusobacterium } \\
\text { nucleatum }\end{array}$ & $\begin{array}{l}\text { Antibiotics, } \\
\text { metronidazole, } \\
\text { enoxaparin, } \\
\text { warfarin }\end{array}$ & $\begin{array}{l}\text { Complete } \\
\text { resolution of } \\
\text { symptoms }\end{array}$ & $\begin{array}{l}\text { Continued } \\
\text { improvement }\end{array}$ & {$[12]$} \\
\hline Case 5 & $\begin{array}{l}\text { Cheung, } \\
\text { et al. }\end{array}$ & $24 \mathrm{y} / \mathrm{M}$ & $\begin{array}{l}\text { Fever, neck pain, } \\
\text { rhinorrhea, sore } \\
\text { throat, and } \\
\text { tender cervical } \\
\text { lymph nodes }\end{array}$ & $\begin{array}{l}\text { Hepatic vein } \\
\text { thrombosis }\end{array}$ & $\begin{array}{l}\text { Blood culture } \\
\text { showed } \\
\text { Fusobacterium } \\
\text { nucleatum }\end{array}$ & $\begin{array}{c}\text { Antibiotics, } \\
\text { anticoagulants }\end{array}$ & $\begin{array}{l}\text { Resolution } \\
\text { of } \\
\text { symptoms }\end{array}$ & $\begin{array}{c}\text { Not } \\
\text { mentioned }\end{array}$ & {$[13]$} \\
\hline Case 6 & Iwata, et al. & $23 \mathrm{y} / \mathrm{M}$ & $\begin{array}{l}\text { Fever, sore } \\
\text { throat, neck pain, } \\
\text { and chest pain }\end{array}$ & $\begin{array}{c}\text { Right } \\
\text { internal } \\
\text { jugular vein }\end{array}$ & $\begin{array}{l}\text { BAL culture } \\
\text { showed } \\
\text { Fusobacterium } \\
\text { nucleatum }\end{array}$ & Antibiotics & $\begin{array}{l}\text { Resolution } \\
\text { of } \\
\text { symptoms }\end{array}$ & $\begin{array}{c}\text { Not } \\
\text { mentioned }\end{array}$ & {$[14]$} \\
\hline
\end{tabular}

BAL: Bronchoalveolar lavage.

between 0 and 18\%. An average delay of 5 days from the time of admission to diagnosis has been reported. Almost $60-70 \%$ of cases require intensive care admissions [15, 16]. 37\% of cases require intubation, and severe cases often require extracorporeal membrane oxygenation [17]. An average hospital stay of patients with Lemierre's syndrome is 3 weeks. Our case is a good addition to the existing pool of data about this forgotten disease.

\section{Conclusion}

Lemierre's syndrome presents initially with an oropharyngeal infection that causes septic thrombophlebitis of the neck veins and affects organs such as the lungs, liver, joints, kidney, and brain. It has potentially lethal consequences if intervention is delayed. Rapid and accurate diagnosis is done by early microbial culture, CT/MRI, and ultrasound, which facilitates aggressive treatment and a favorable outcome. The misdiagnosis or delayed diagnosis or faulty treatment increases the risk of mortality in this rare condition. Physicians of all specialties should have a low threshold for diagnosing Lemierre's syndrome in the light of distinctive signs and symptoms, including clinical, imaging, and blood cultures.
Antibiotics are recognized as the primary mode of treatment. The use of anticoagulant in treating Lemierre's disease is debatable, and more prospective randomized trials are needed to come to a clear consensus.

\section{Conflicts of Interest}

The authors declare there are no conflicts of interest.

\section{References}

[1] R. Chapman and A. Tully, "A life-threatening sore throat," The Lancet, vol. 364, no. 9428, p. 112, 2004.

[2] J. Ibrahim, M. B. Noureddin, A. Lootah, A. Al Khalidi, G. Ghatasheh, and H. Al Tatari, "A rare case of lemierre-like syndrome: a case report and literature review," Case Reports in Pediatrics, vol. 2018, pp. 1-3, 2018.

[3] C. V. Ngu, J. Rohaizam, and Y. Jong, "Lemierre's syndrome: a persistent unusual neck pain and swelling," Malaysian Family Physician: The Official Journal of the Academy of Family Physicians of Malaysia, vol. 13, no. 1, p. 37, 2018.

[4] J. A. Coultas, N. Bodasing, P. Horrocks, and A. Cadwgan, "Lemierre's syndrome: recognising a typical presentation of a rare condition," Case Reports in Infectious Diseases, vol. 2015, 2015. 
[5] W. Eilbert and N. Singla, "Lemierre's syndrome," International Journal of Emergency Medicine, vol. 6, no. 1, p. 40, 2013.

[6] C. Colbert, M. McCormack, W. Eilbert, and L. Bull, "Lemierre syndrome as a complication of Laryngeal Carcinoma," Clinical Practices and Cases in Emergency Medicine, vol. 2, no. 1, pp. 78-81, 2018.

[7] N. S. Hamza, J. Farrel, M. Strauss, and R. A. Bonomo, "Deep fascial space infection of the neck: a continuing challenge," Southern Medical Journal, vol. 96, no. 9, pp. 928-932, 2003.

[8] N. A. Farrel, R. Knapp-Clevenger, T. Hays, and M. J. MancoJohnson, "Lemierre's and Lemierre's-like syndromes in Children: survival and Thromboembolic outcomes," Pediatrics, vol. 116, no. 4, pp. e543-e548, 2005.

[9] P. Bondy and T. Grant, "Lemierre's syndrome: what are the roles for anticoagulation and long-term antibiotic therapy?" Annals of Otology, Rhinology \& Laryngology, vol. 117, no. 9, pp. 679-683, 2008.

[10] M. D. Williams, C. A. Kerber, and H. F. Tergin, "Unusual presentation of Lemierre's syndrome due to Fusobacterium nucleatum," Journal of Clinical Microbiology, vol. 41, no. 7, pp. 3445-3448, 2003.

[11] S. Takahashi, S. Ito, S. Tagashira, K. Yasui, Y. Watanabe, and K. Nakashima, "A case of corticosteroid-responsive Lemierre syndrome with clivus osteomyelitis and a mass in the cavernous sinus-suprasellar region," Rinsho Shinkeigaku, vol. 55, no. 5, pp. 327-332, 2015.

[12] A. P. Wong, M. L. Duggins, and T. Neil, "Internal jugular vein septic thrombophlebitis (lemierre syndrome) as a complication of pharyngitis," The Journal of the American Board of Family Medicine, vol. 28, no. 3, pp. 425-430, 2015.

[13] W. Y. Cheung and J. Bellas, "Case report: lemierre syndrome presenting with fever and pharyngitis," American Family Physician, vol. 75, no. 75, pp. 979-80, 2007.

[14] N. Iwata, N. Komiya, F. Uchiyama-Nakamura, and K. Ohnishi, "Lemierre syndrome: a Japanese patient returning from Thailand," Journal of Infection and Chemotherapy, vol. 16, no. 3, pp. 213-215, 2010.

[15] E. A. Goldberg, T. Venkat-Ramani, M. Hewit, and H. F. Bonilla, "Epidemiology and clinical outcomes of patients with Fusobacterium bacteraemia," Epidemiology and Infection, vol. 141, no. 2, pp. 325-329, 2013.

[16] P. D. Karkos, S. Asrani, C. D. Karkos et al., "Lemierre's syndrome: a systematic review," The Laryngoscope, vol. 119, no. 8, pp. 1552-1559, 2009.

[17] S. S. Assimakopoulos and K. Mason, "Extra-corporeal membrane oxygenation in a patient with Fusobacterium sepsis: a case report and review of literature," Annals of Thoracic and Cardiovascular Surgery, vol. 17, no. 4, pp. 397399, 2011. 